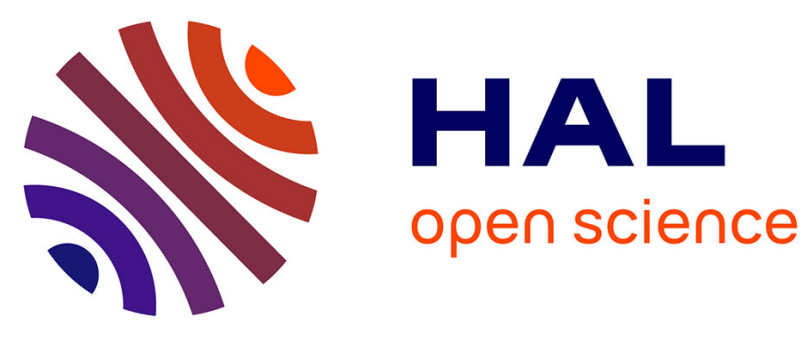

\title{
Effect of the Buffer on the Buildup and Stability of Tannic Acid/Collagen Multilayer Films Applied as Antibacterial Coatings
}

Muhammad Haseeb Iqbal, André Schroder, Halima Kerdjoudj, Christian Njel, Bernard Senger, Vincent Ball, Florent Meyer, Fouzia Boulmedais

\section{To cite this version:}

Muhammad Haseeb Iqbal, André Schroder, Halima Kerdjoudj, Christian Njel, Bernard Senger, et al.. Effect of the Buffer on the Buildup and Stability of Tannic Acid/Collagen Multilayer Films Applied as Antibacterial Coatings. ACS Applied Materials \& Interfaces, 2020, 10.1021/acsami.0c04475 . hal02567386

\section{HAL Id: hal-02567386 \\ https://hal.science/hal-02567386}

Submitted on 7 May 2020

HAL is a multi-disciplinary open access archive for the deposit and dissemination of scientific research documents, whether they are published or not. The documents may come from teaching and research institutions in France or abroad, or from public or private research centers.
L'archive ouverte pluridisciplinaire HAL, est destinée au dépôt et à la diffusion de documents scientifiques de niveau recherche, publiés ou non, émanant des établissements d'enseignement et de recherche français ou étrangers, des laboratoires publics ou privés. 


\section{Effect of the Buffer on the Buildup and Stability of}

\section{Tannic acid/Collagen Multilayer Films applied as}

\section{antibacterial coatings}

Muhammad Haseeb Iqbal, ${ }^{1}$ André Schroder, ${ }^{1}$ Halima Kerdjoudj,,${ }^{2,3}$ Christian Njel, ${ }^{4}$ Bernard

Senger, ${ }^{5,6}$ Vincent Ball, ${ }^{5,6}$ Florent Meyer, ${ }^{5,6}$ Fouzia Boulmedais ${ }^{1, *}$

1. Université de Strasbourg, CNRS, Institut Charles Sadron, UPR 22, 67034 Strasbourg Cedex 2,

France.

2. Université de Reims Champagne Ardenne, EA 4691, Biomatériaux et Inflammation en Site Osseux (BIOS), SFR CAP Santé (FED4231), 51100 Reims, France.

3. UFR d'Odontologie, Université de Reims Champagne Ardenne, 51100 Reims, France.

4. Institute for Applied Materials (IAM) and Karlsruhe Nano Micro Facility (KNMF), Karlsruhe Institute of Technology (KIT), D-76344 Eggenstein-Leopoldshafen, Germany

5. Institut National de la Santé et de la Recherche Médicale, UMR_S 1121, 67085 Strasbourg Cedex, France.

6. Université de Strasbourg, Faculté de Chirurgie Dentaire, 67000 Strasbourg, France.

KEYWORDS: polyphenols, layer-by-layer, polyelectrolytes, antimicrobial, citrate 


\section{ABSTRACT}

The deposition of polyelectrolyte multilayers, obtained by the Layer-by-layer (LbL) method, is a well-established technology to design biocompatible and antibacterial coatings aimed at preventing implant-associated infections. Several types of LbL films have been reported to exhibit anti-adhesive and/or antibacterial (contact-killing or release-killing) properties governed not only by the incorporated compounds but also by their buildup conditions or their postbuildup treatments. Tannic acid (TA), a natural polyphenol, is known to inhibit the growth of several bacterial strains. In this work, we developed TA/collagen (TA/COL) LbL films built in acetate or citrate buffers at $\mathrm{pH}$ 4. Surprisingly, the used buffer impacts not only the physicochemical but also the antibacterial proper-ties of the films. When incubated in physiological conditions, both types of TA/COL films released almost the same amount of TA depending on the last layer and showed an antibacterial effect against Staphylococcus aureus only for citratebuilt films. Because of their granular topography, TA/COL citrate films exhibited an efficient release-killing effect with no cytotoxicity towards human gingival fibroblasts. Emphasis is put on a comprehensive evaluation of the physico-chemical parameters driving the buildup and the antibacterial property of citrate films. Specifically, complexation strengths between TA and COL are different in the presence of the two buffers affecting the LbL deposition. This work constitutes an important step toward the use of polyphenols as antibacterial agent when incorporated in LbL films. 


\section{INTRODUCTION}

Development of multifunctional coatings has drawn a great attention in the last few decades because of their broad spectrum of applications. In biomedical related fields, surface properties like antimicrobial activity and biocompatibility are highly desired to subsequent tissue integration of implants. ${ }^{1}$ Medical devices are most likely to undergo nosocomial infections because of local contamination during the surgery. Such infections are triggered by bacterial adhesion on the surface of the implant followed by their proliferation and matrix synthesis leading to the formation of a biofilm. Prevention of the early attachment and proliferation of bacteria has created huge interest and led to the development of antibacterial coatings. ${ }^{2-3}$

Among the surface modification techniques, the Layer-by-Layer (LbL) method is a versatile way to functionalize surfaces by the alternated deposition of oppositely charged polyelectrolytes generally by dip coating. ${ }^{4}$ It is an attractive method as it can be applied to any type of substrate, even neutral polymers. ${ }^{5}$ The coherence of these films is usually due to the electrostatic interactions between the chains. Hydrogen bonded LbL films were also reported. ${ }^{6-7}$ The adhesion strength between the LbL films and the substrate can be improved by grafting of the first deposited layer. The growth of polyelectrolyte multilayer (PEMs) films is either linear or exponential with the number of deposition steps. Performed at room temperature using aqueous solutions, the LbL method allows the development of biocompatible and bioactive thin films, in particular with antimicrobial property. ${ }^{8-9}$

Several types of LbL films have been reported to exhibit anti-adhesive and/or antimicrobial (contact-killing or release killing) properties governed not only by the incorporated compounds but also by the buildup conditions or post-buildup treatments. Adhesion-resistant LbL films are 
either highly hydrophilic preventing the close contact of bacteria ${ }^{10}$ or have specific stiffnesses to prevent bacterial adhesion. ${ }^{11-12}$ The hydrophilicity ${ }^{13}$ of the films, as well as their rigidity, ${ }^{11,14}$ can be tuned by the adjustment of physico-chemical parameters of the film buildup, such as $\mathrm{pH}$ and/or ionic strength. Knowing that bacterial membranes are negatively charged, most of contact-killing LbL films were developed ending with positively charged polyelectrolytes ${ }^{15-18}$ or quaternary ammonium containing polymers. ${ }^{19-20}$ The bactericidal effect of these films is governed by the surface composition ${ }^{13,16}$ or the diffusion of polycations in the films. ${ }^{17-18,21}$ Release-killing LbL films leach out antibacterial agents, by direct diffusion ${ }^{22-23}$ or by film degradation due to hydrolysis, ${ }^{24-25} \mathrm{pH}^{26}$ or enzymes. ${ }^{27}$

Since a few decades, an intensive research is being carried out to explore the potential of polyphenols, found in plants as secondary metabolites, as antibacterial and antioxidants agents. Tannic acid (TA) is a polyphenol (Scheme 1a) known to inhibit the growth of bacteria. ${ }^{28}$

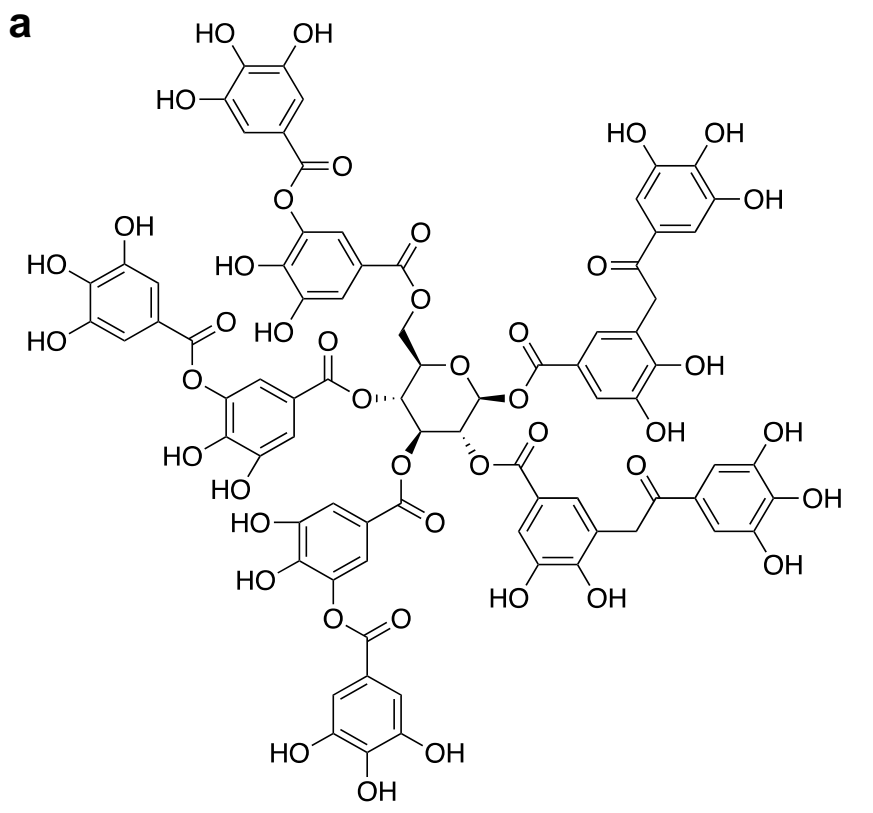<smiles>CC(=O)O</smiles><smiles>O=C(O)CC(O)(CC(=O)O)C(=O)O</smiles>

Scheme 1: Chemical formulae of (a) TA and buffer used in this study (b) acetic acid and (c) citric acid. 
TA based LbL films were mainly developed to obtain antifouling, ${ }^{29}$ self-healing ${ }^{30}$ and hemostatic ${ }^{31}$ properties. Except one study, ${ }^{32}$ antibacterial properties of TA based LbL films were always obtained with the incorporation of antibacterial compounds, such as antibiotics, ${ }^{33}$ peptides $^{34}$ or chitosan. ${ }^{35}$ Park et al. ${ }^{32}$ developed sprayed TA/Fe(III) films as antifungal coating for shoe insoles. In this study, we report buffer dependent antibacterial property of LbL films based on TA and collagen type I (COL). COL is the most abundant extracellular matrix protein present in the mammalian body and can be assembled in LbL manner with different polyanions. ${ }^{36-40}$ Because of solubility issues of $\mathrm{COL}$, TA/COL films were built at $\mathrm{pH} 4$ using either acetate buffer or citrate buffer (Scheme 1b and c) to prepare TA and COL solutions. Acetic acid is a monoprotic acid with a pKa at 4.7. Citric acid is a triprotic acid with three different pKa at 3.1, 4.8 and 6.4 leading to only one deprotonated and two protonated carboxylic acid at $\mathrm{pH}$ 4. In this form, citric acid is thus able to form hydrogen bonds and electrostatic interactions. Surprisingly, the used buffer impacts not only the physico-chemical properties but also the antibacterial effect of TA/COL films. Emphasis is given on a comprehensive evaluation of the physico-chemical parameters driving the buildup and the antibacterial property of the films. Specifically, complexation strengths between TA and COL are different in the presence of acetate or citrate affecting the LbL deposition.

\section{EXPERIMENTAL SECTION}

Materials. Collagen (COL, purified type I from calf, Symatese, France), tannic acid (TA, $\mathrm{M}_{\mathrm{w}}=1701.2 \mathrm{~g} / \mathrm{mol}$, Sigma-Aldrich, France), poly(ethylene imine) (PEI, branched, 30\% w/w aq. solution, $\mathrm{M}_{\mathrm{w}}=50000-100000 \mathrm{~g} / \mathrm{mol}$, Alfa Aesar, Germany), acetic acid $\left(\mathrm{M}_{\mathrm{w}}=60.05 \mathrm{~g} / \mathrm{mol}\right.$, Sigma-Aldrich), citric acid monohydrate $\left(\mathrm{M}_{\mathrm{w}}=210.14 \mathrm{~g} / \mathrm{mol}\right.$, Sigma-Aldrich), sodium citrate 
tribasic dihydrate $\left(\mathrm{M}_{\mathrm{w}}=294.10 \mathrm{~g} / \mathrm{mol}\right.$, Sigma-Aldrich), Dulbecco's phosphate buffer saline (PBS, L0615, Dominique Dutscher, France), sodium dodecyl sulfate (Prolabo, Poland), HEPES sodium salt $\left(\mathrm{M}_{\mathrm{w}}=260.29 \mathrm{~g} / \mathrm{mol}\right.$, Sigma-Aldrich), $\mathrm{NaCl}$ (VWR), $\mathrm{HCl}$ and $\mathrm{NaOH}$ (Sigma-Aldrich) were used as received.

TA/COL layer-by-layer buildup. TA/COL films were built on a PEI precursor layer. The PEI solution was prepared at $0.1 \mathrm{mg} / \mathrm{mL}$ in $0.15 \mathrm{M} \mathrm{NaCl}$ without $\mathrm{pH}$ adjustment. Acetate buffer was prepared at $\mathrm{pH} 4$ with $0.1 \mathrm{M}$ acetic acid. Citrate buffer was prepared at $\mathrm{pH} 4$ by mixing $59 \mathrm{~mL}$ $0.1 \mathrm{M}$ of citric acid and $41 \mathrm{~mL}$ of $0.1 \mathrm{M}$ sodium citrate solutions. TA and COL were prepared at $0.1 \mathrm{mg} / \mathrm{mL}$ using either acetate or citrate buffer. TA solutions were prepared freshly, and COL solutions were prepared and left under stirring overnight before use. $100 \mu \mathrm{L}$ of compound (respectively buffer) were deposited on the substrate at each deposition (respectively rinsing) steps. PEI was used as a first layer with 5 min of deposition step followed by two rinsing steps (5 min) with $0.15 \mathrm{M} \mathrm{NaCl}$ and acetate or citrate buffer. TA deposition time was of 5 min and COL deposition of $15 \mathrm{~min}$ with a rinsing step of $5 \mathrm{~min}$ with the same solution used to dissolve the compounds. The obtained PEI-(COL/TA $)_{n}$ were denoted $(\mathrm{COL} / \mathrm{TA})_{\mathrm{n}}$ acetate (resp. citrate) films when built with compound solutions prepared in acetate (resp. citrate) buffer.

Quartz crystal microbalance with dissipation (QCM-D). TA/COL film buildup was followed by quartz crystal microbalance with dissipation (QCM-D) using QCM-D E1 (Q-Sense, Goteborg, Sweden) with the QCM open cell allowing the pipetting of the solutions. $\mathrm{SiO}_{2}$ coated quartz crystal (Microvacuum, Budapest, Hungary) was excited at its fundamental frequency (about 5 $\mathrm{MHz}$ ), as well as at the third, fifth, seventh and ninth overtones (denoted by $v=3,5,7$ and 9) corresponding to $15,25,35$ and $45 \mathrm{MHz}$, respectively. The results corresponding to changes in the frequency shifts $\left(\Delta f_{v} / v\right)$ and dissipation $\left(\Delta D_{v}\right)$, obtained from QCM-D experiments, were 
analyzed using the Voigt-Voinova model to determine the film thickness. ${ }^{41}$ The mass density of the film was fixed at $1 \mathrm{~g} / \mathrm{cm}^{3}$, the mass density of the solutions was fixed at $1.009 \mathrm{~g} / \mathrm{cm}^{3}$ and their viscosity at $0.91 \mathrm{mPa} \cdot \mathrm{s} . \mathrm{SiO}_{2}$ coated QCM crystals were treated by UV/Ozone treatment for $15 \mathrm{~min}$ prior to experiment to ensure negatively charged hydrophilic surface. $100 \mu \mathrm{L}$ of compound solution (respectively buffer) were deposited on the crystal at each deposition (respectively rinsing), respectively. PEI was used as a first layer with 5 min of deposition step and 5 min of rinsing step with $0.15 \mathrm{M} \mathrm{NaCl}$. TA deposition time was of $5 \mathrm{~min}$ and $\mathrm{COL}$ deposition of $15 \mathrm{~min}$ to reach a stability of the QCM signal, with a rinsing step of $5 \mathrm{~min}$ with the same solution used to dissolve the compounds. To test the stability of the films in physiological conditions, $(\mathrm{COL} / \mathrm{TA})_{6}-\mathrm{COL}$ acetate and citrate films were put in contact with $350 \mu \mathrm{L}$ of PBS at pH 7.4 overnight, followed by a rinsing step with the buffer.

Atomic force microscopy (AFM). AFM Multimode Nanoscope IV from Bruker (Palaiseau, France) was used to image TA/COL films in the liquid state using silicon nitride coated tips on a gold covered cantilever (Model Scanasyst-Fluid from Bruker, with force constant $k=0.7 \mathrm{~N} / \mathrm{m}$ and frequency $f_{\mathrm{o}}=150 \mathrm{kHz}$ ) in the Peak Force Tapping (ScanAsyst Fluid) mode. The images were obtained at a scan rate of $1 \mathrm{~Hz}$ with a resolution of $256 \times 256$ pixels. The data analysis was performed using NanoScope Analysis Software (version 1.7). After dipping into ethanol/water (50:50 v:v) for $15 \mathrm{~min}$ followed by plasma cleaner treatment for $3 \mathrm{~min}$, silicon wafers were used as substrates for TA/COL buildup. The samples were stored in the buffer before observation. Different areas of the samples were scanned to obtain typical topography images. The roughness of the film was determined using the RMS value given by the Nanoscope software on at least three AFM images $\left(10 \times 10 \mu \mathrm{m}^{2}\right)$. The film thickness was measured by imaging film scratches, obtained using a sharp tweezer, on three different areas perpendicularly to the fast scan axis. We 
define the film thickness as the minimal $\mathrm{z}$ distance between the bare substrate and the surface of the film, which covers the whole substrate.

Isothermal titration calorimetry (ITC). Nano ITC standard volume (TA instruments, USA) was used to record interaction isotherms during the titration of COL by TA in both acetate and citrate buffers at $\mathrm{pH}$ 4. The sample and reference cell volumes were $1 \mathrm{~mL}$, and the syringe volume was $250 \mu \mathrm{L}$. The reference cell was filled with ultrapure water (MilliQ) and the sample cell with a COL solution at $0.62 \mathrm{mM}$. A $1.645 \mathrm{mM}$ TA solution (titrant) was placed in a-motor driven syringe, which was set on rotation $(300 \mathrm{rpm})$ to ensure proper mixing of the reactants. $250 \mu \mathrm{L}$ of the titrant were added in the sample cell in 25 injection steps of $10 \mu \mathrm{L}$ each with a stabilization time of $1200 \mathrm{~s}$ between two consecutive injections. Different controls were performed i.e. buffer in buffer, titrant dilution in buffer and buffer in COL. The latter did not show significant difference with the buffer in buffer experiment. The heat associated to the titrant-in-buffer control was subtracted from the heat of the COL/TA association. TA/COL mixture solutions, at 0.28 TA/COL molar ratio in citrate and acetate buffers, were observed by AFM in the Peak Force Tapping (ScanAsyst Air) mode in dry state. The samples were 8-fold diluted in their respective buffer. $50 \mu \mathrm{L}$ of the diluted solution was put in contact on the MICA followed by two steps of rinsing with water at $\mathrm{pH} 4$ and a drying step at room temperature.

Circular dichroism (CD) spectroscopy. CD spectra were collected using a JASCO J-810 spectropolarimeter. The spectra were recorded between 190 and $400 \mathrm{~nm}$ with a bandwidth of 1 $\mathrm{nm}$, NIR bandwidth of $20 \mathrm{~nm}$, number of accumulations 3, and the scanning speed of 100 $\mathrm{nm} / \mathrm{min}$. After UV/Ozone treatment for $15 \mathrm{~min}$, quartz lamellae were used as substrates to build TA/COL films. The background was measured with uncoated quartz lamella. CD spectra were recorded in the dry state with data pitch of $1 \mathrm{~nm}$ on the light wavelength. 
Attenuated total reflection - Fourier transform infrared spectroscopy (ATR - FTIR). FTIR experiments were performed on a Vertex 70 spectrometer (Bruker, Germany) using a DTGS detector. Spectra were recorded in the Attenuated Total Reflection (ATR) mode using a ZnSe crystal $\left(45^{\circ}\right.$ trapezoidal, 6 reflections, dimensions $\left.72 \times 10 \times 6 \mathrm{~mm}^{3}\right)$ by averaging 128 interferograms between 800 and $4000 \mathrm{~cm}^{-1}$ at $2 \mathrm{~cm}^{-1}$ resolution, using Blackman-Harris threeterm apodization and Bruker OPUS/IR software (version 7.5). FTIR spectra of TA/COL films were recorded after each polyelectrolyte deposition step followed by the rinsing step. After buildup, FTIR spectra were recorded during the contact with PBS buffer for $24 \mathrm{~h}$. All the solutions were prepared in deuterated buffer to avoid the interference of the water peak in the amide I region of collagen. The background spectrum was taken with a bare $\mathrm{ZnSe}$ crystal in contact with the buffer used for the film buildup.

X-ray Photoelectron Spectroscopy. A the Thermo Scientific K-alpha+ spectrometer was used to acquire the XPS spectra. The monochromatic Al Ka line was used as X-ray excitation (1486.6 $\mathrm{eV}$ ) with pass energy of $50 \mathrm{eV}$ to obtain high resolution spectra. The samples were analyzed using a microfocused, monochromated AlK $\alpha$ X-ray source (400 $\mu \mathrm{m}$ spot size). XPS spectra were fit with one or more Voigt profiles (binding energy uncertainty: $\pm 0.2 \mathrm{eV}$ ) and Scofield sensitivity factors were applied for quantification. ${ }^{42}$ All spectra were referenced to the $\mathrm{C} 1 \mathrm{~s}$ peak $(\mathrm{C}-\mathrm{C}, \mathrm{C}-$ $\mathrm{H})$ at $285.0 \mathrm{eV}$ binding energy controlled by means of the photoelectron peaks of metallic $\mathrm{Cu}$, $\mathrm{Ag}$, and $\mathrm{Au}$ respectively. Carbon $(\mathrm{C} 1 \mathrm{~s})$ spectra were recorded at the beginning and after each resolution analysis to check the absence of any sample degradation under irradiation. XPS analyses were performed on $(\mathrm{COL} / \mathrm{TA})_{7}$ films in comparison to $\mathrm{COL}$ and $\mathrm{TA}$ monolayers, obtained by dipping. All the samples were rinsed with water at $\mathrm{pH} 4$ before the drying step to avoid salt deposition from the supernatant. The COL/TA molar ratio of the films was calculated 
using the amount of oxidized carbon (named $C_{\mathrm{ox}}$ ), corresponding to the 286, 288 and $289 \mathrm{eV}$ peaks, present on all compounds and the total amount of nitrogen, present only for COL. The details about calculations can be found in the SI.

TA release in physiological conditions. TA release from TA/COL films in PBS buffer was followed by measuring the absorbance intensity at $277 \mathrm{~nm}$ using a spectrofluorometer (SAFAS Xenius XC). COL used in the study showed no absorption at this wavelength. First, a calibration curve of TA was obtained by measuring the absorbance intensity at $277 \mathrm{~nm}$ for different concentrations of TA in PBS buffer. TA/COL films were prepared on $12 \mathrm{~mm} \emptyset$ glass slides and stored in the buffer used for their buildup. $500 \mu \mathrm{L}$ of PBS buffer at $\mathrm{pH} 7.4$ at room temperature was put in contact with the films. $100 \mu \mathrm{L}$ of the supernatant were withdrawn and put in an UVStar® 96-well plate (Greiner bio-one) to measure the absorbance at $277 \mathrm{~nm}$. The remaining 400 $\mu \mathrm{L}$ supernatant was replaced by $500 \mu \mathrm{L}$ of PBS buffer. Similar experiments were performed using HEPES $10 \mathrm{mM} \mathrm{pH} 7.4$ at $37^{\circ} \mathrm{C}$, without and with additional $150 \mathrm{mM} \mathrm{NaCl}$, to mimic the medium used in microbiology and in cell culture, respectively.

Antimicrobial assay. The antibacterial activity of $(\mathrm{COL} / \mathrm{TA})_{6}-\mathrm{COL}$ and $(\mathrm{COL} / \mathrm{TA})_{7}$ films, prepared on $12 \mathrm{~mm} \emptyset$ glass substrates using acetate and citrate buffers, were determined towards Staphylococcus aureus (S. aureus, ATCC ${ }^{\circledR} 25923^{\mathrm{TM}}$ ), a gram-positive strain and Escherichia Coli (E. coli, $\left.\mathrm{ATCC}^{\circledR} 25922^{\mathrm{TM}}\right)$, gram-negative train. One colony of bacteria was pre-cultured aerobically in Mueller-Hinton (MH) broth ( $\mathrm{pH}$ 7.2-7.6, Merck, Darmstadt, Germany) in an incubator under agitation for $24 \mathrm{~h}$ at $37^{\circ} \mathrm{C}$. The pre-culture was diluted using $\mathrm{MH}$ broth to an optical density at $620 \mathrm{~nm}\left(\mathrm{OD}_{620}\right)$ of 0.001 corresponding to $8 \times 10^{5} \mathrm{CFU} / \mathrm{mL}$ just before use. Before the test the TA/COL films were exposed $20 \mathrm{~min}$ to UV radiation. TA/COL films were incubated with $400 \mu \mathrm{L}$ of bacterial solution $\left(\mathrm{OD}_{620}=0.001\right)$ in an incubator at $37^{\circ} \mathrm{C}$. 
Quantification of the bacteria in their planktonic state after contact with film samples for 24 and $48 \mathrm{~h}$, was performed by using a serial dilution and counting method. Bacterial suspensions in contact with the samples were diluted, by serial dilution, between $10^{2}$ to $10^{5}$ times. $100 \mu \mathrm{L}$ of each dilution were spread uniformly on nutrient agar plates and the number of colony forming units (CFU) were counted after $24 \mathrm{~h}$ incubation. Quantification was performed on the first plate showing formation of isolated CFUs.

Scanning electron microscopy (SEM). SEM (FEI Quanta ${ }^{\mathrm{TM}} 250$ FEG) was used to image TA/COL films after $24 \mathrm{~h}$ of contact with $\mathrm{MH}$ medium, with and without bacterial inoculation. After a rinsing step in PBS, TA/COL samples were dipped in $400 \mu \mathrm{L}$ of paraformaldehyde $4 \%$ (PFA) for $15 \mathrm{~min}$ to fix the bacterial cells on the film surface, followed by three PBS rinsing steps, three water rinsing steps, water/ethanol rinsing steps using 70\%, 95\% and 100\% ethanol. The samples were treated with hexamethyldisilazane (HMDS)/ethanol mixture (50:50 v:v) for 5 min followed by two rinsing steps with pure HMDS (5 min each). After removal of the HMDS solution, the samples were dried under a laminar flow fume-hood and metalized with gold using a sputter coater.

Cytotoxicity tests. The cytotoxic effect of $(\mathrm{COL} / \mathrm{TA})_{6}-\mathrm{COL}$ and $(\mathrm{COL} / \mathrm{TA})_{7}$ films, prepared on $14 \mathrm{~mm} \varnothing$ glass slides using acetate and citrate buffers, were determined towards fibroblasts derived from human gingiva (HGFs). Human gingiva harvesting was approved ethically and methodologically by our local Research Institution and was conducted with informed patients (written consent) in accordance with the usual ethical legal regulations (Article R 1243-57). All procedures were done in accordance with our authorization and registration number DC-20142262 given by the National "Cellule de Bioéthique". HGFs were seeded on the top of substrates at $10^{4}$ cells $/ \mathrm{cm}^{2}$ and maintained in complete culture medium (DMEM, supplemented with $10 \%$ 
decomplemented fetal bovine serum (FBS), 1\% Penicillin/Streptomycin/Amphotericin B and 1\% Glutamax ${ }^{\circledR}$ (v/v, Gibco)] for 9 days. WST-1 cell proliferation assay (Roche Diagnostics, France) was performed after 2, 5 and 9 days of culture. Absorbance was measured at $490 \mathrm{~nm}$ using a FLUOstar Omega microplate reader (BMG Labtech) against a background control as blank with a reference wavelength of $750 \mathrm{~nm}$. After 2, 5 and 9 days of culture, DNA was extracted using the MasterPureTMDNA Purification Kit (Epicentre®Biotechnologies) in accordance with the manufacturer protocol. Extracted DNA was assessed by measuring the absorbance at 260 and $280 \mathrm{~nm}$ (Nanodrop®, Thermo Scientific) with a 260/280 nm absorbance ratio for all measured samples comprised between 1.8 and 2. Cytoskeleton staining with Alexa® Fluor-488 conjugated-Phalloidin®. After 15 days of culture, fibroblasts were fixed with $4 \%$ (w/v) paraformaldehyde for $15 \mathrm{~min}$ at room temperature, permeabilized with $0.5 \%(\mathrm{v} / \mathrm{v})$ Triton X-100 for 15 min and finally stained with Alexa® Fluor- 488 conjugated-Phalloidin® (Invitrogen, 1/100) for $30 \mathrm{~min}$. Nuclei were counter-stained with 4,6-diamidino-2-phenylindole (DAPI, 100

$\mathrm{ng} / \mathrm{mL}, 1: 10,000$ dilution) for $5 \mathrm{~min}$. Stained cells were then mounted and imaged by fluorescence microscopy (Zeiss microscopy, $\times 20)$.

\section{RESULTS AND DISCUSSION}

TA/COL film buildup in acetate and citrate buffers. The buildup of TA/COL LbL films was monitored in situ by QCM-D using TA and COL solutions prepared at $\mathrm{pH} 4$ in acetate or citrate buffers (Figure S1a-b in the Supporting Information, SI). The film thickness was calculated by fitting the QCM-D data using the Voigt-Voinova model (Figure 1a). In contrast to the normalized frequency shift, the evolution of the film thickness as a function of adsorbed layer 
showed no level off but rather a change in the slope of the growth. (COL/TA) ${ }_{6}$-COL films acetate and citrate films reached 333 and $150 \mathrm{~nm}$ in thickness, respectively.
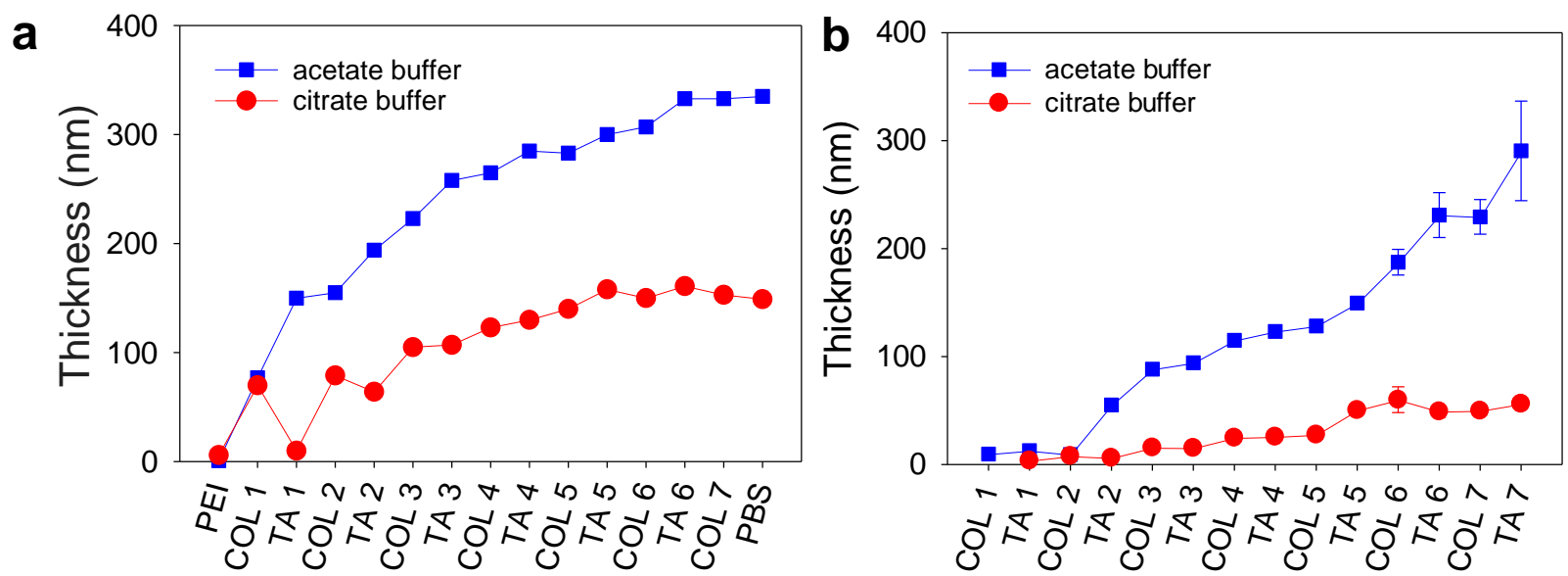

C

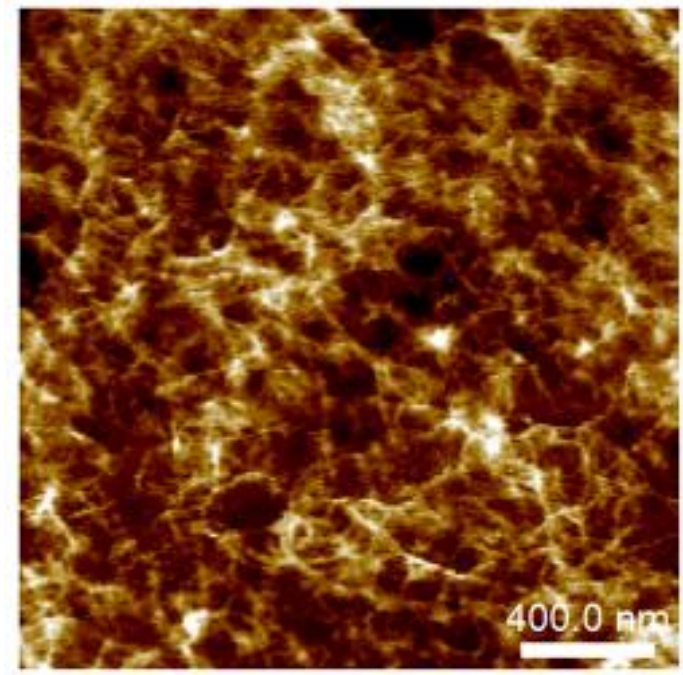

d

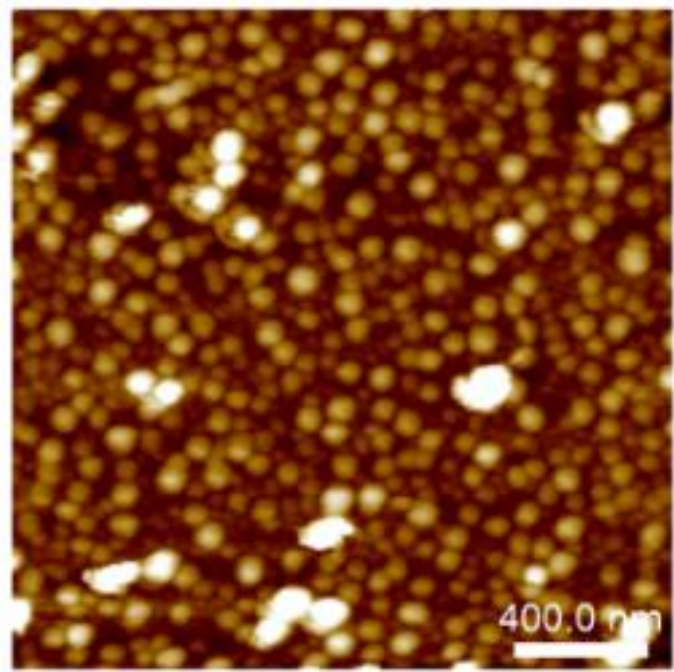

Figure 1: Evolution of the thickness of TA/COL films built in acetate $(\boldsymbol{\square})$ and citrate ( $\bullet$ ) buffers at $\mathrm{pH} 4$ as a function of each deposited layer (a) determined with the Voigt-Voinova model using the QCM-D data, at the last step, PBS buffer was put in contact for $14 \mathrm{~h}$, (b) determined by AFM in liquid state. Typical AFM images (z scale $50 \mathrm{~nm}$ ), obtained in Peak Force Tapping mode (ScanAsyst) and in the liquid state, $(\mathrm{COL} / \mathrm{TA})_{2}$ films built at $\mathrm{pH} 4$ in acetate (c) and citrate (d) buffers. 
The normalized frequency shift $\left(\Delta f_{\mathfrak{V}} / v\right)$ measures the contributions from adsorbed material and bound water molecules whereas the dissipation change $\left(\Delta D_{v}\right)$ represents the rigidity of the coatings, related to the hydration and conformations of adsorbed material. ${ }^{43}$ When $\Delta D_{v}$ versus $\Delta f_{\mathfrak{}} / v$ are plotted, two phases are displayed with significantly different slopes (Figure S2c-d in the SI). The first phase, with the highest slope, corresponds to loosely bound (macro)molecules with a large amount of hydrodynamically coupled water. In the second phase, $\Delta D_{v}$ slightly increases with the adsorbed material. The amount of hydrodynamically trapped water is reduced creating a denser coating. ${ }^{44}$ Bound water loss of TA/COL films is compensated by adsorbed materials leading to stabilization of the frequency shift. AFM was used to investigate the thickness and the topography of TA/COL films in liquid state. The cross-section of TA/COL scratched films allowed to determine the film thickness in liquid state. The film thickness was defined as the minimal $\mathrm{z}$ distance between the bare substrate and the surface of the film that covers the whole substrate (Figure S3 in the SI). In wet state, TA/COL acetate films have a higher thickness than citrate films reaching $(291 \pm 46) \mathrm{nm}$ and $(56 \pm 5) \mathrm{nm}$ after 7 bilayers, respectively (Figure 1b). The water uptake of TA/COL film was determined by comparing the film thickness in dry state and in wet state. In the case of $(\mathrm{COL} / \mathrm{TA})_{6}-\mathrm{COL} \mathrm{LbL}$, acetate films swell by $388 \%$ with an increase in thickness from $(59 \pm 4)$ to $(229 \pm 16) \mathrm{nm}$ from dry to wet. Citrate films swell by $294 \%$ with an increase in thickness from $(17 \pm 2)$ to $(50 \pm 4) \mathrm{nm}$. A strong difference in water uptake is observed between both types of film in accordance with the difference in dissipation values measured by QCM-D. The high water adsorption is explained by the ability of TA to form hydrogen bonds with water molecules. ${ }^{45}$ This ability is probably compromised by the presence of citrate interacting with TA which leads to less hydrated films. Figure 1c-d shows the typical topography of TA/COL films. Fibrillary structures were observed 
for acetate films and granular structures for citrate films throughout the film buildup (Figure S4 in the SI). In citrate buffer, the size of the granular structures increases with the number of bilayers. In acetate buffer, the fibrillary structures are progressively hidden with an increase in the film thickness rendering their observation more and more difficult. TA/COL acetate films show a roughness between 10 and $25 \mathrm{~nm}$ all along the buildup, representing not more than $10 \%$ of the film thickness (Figure S5 in the SI). The roughness of TA/COL citrate film increases reaching around $50 \mathrm{~nm}$ after 7 bilayers. The thicknesses of TA/COL acetate films are similar when determined by QCM-D and AFM. In contrast, the high roughness of citrate films increased the hydrodynamic thickness determined by QCM-D in comparison to the core thickness determined by AFM (compare Figure 1a and 1b). Intensities of COL and TA bands, measured by FTIR, increase after each deposition cycle which demonstrates the layer-by-layer buildup of TA/COL (Figure S6 in the SI). CD spectra showed that the triple helix structure of COL seems to be impacted in TA/COL films when built in acetate buffer in contrast to citrate one (Figure S7 in the SI).

Insight into the nature of TA/COL complexation. The buffers used to dissolve COL and TA give rise to TA/COL films with two different buildup regimes and topographies. This effect might originate from the modification in the interactions between COL and TA dissolved in these two different buffers. Polyphenols can have multiple interactions with proteins depending on their physico-chemical parameters, such as molecular weight, hydrophobicity and isoelectric point. ${ }^{46}$ Tannins are known to interact with collagen ${ }^{47}$ and other proline-rich proteins ${ }^{48}$ through both hydrogen bonding and hydrophobic interactions. To better elucidate the distinct physicochemical properties of TA/COL films in the two buffers, we performed ITC experiments to investigate COL and TA interactions. The heat of complexation was measured by adding 
aliquots of TA solution into a cell containing COL solution. The molar enthalpy change $\left(\Delta H_{o b s}\right)$ was calculated from the heat measured at each step of the titration subtracting the heat of the control experiments, i.e. buffer in buffer and titrant dilution in buffer (Figure 2). For both buffers, the titration plots of $\Delta H_{o b s}$ is not a typical sigmoidal curve specific to antigen-antibody interactions. This precludes the fitting of the curves by stoichiometric binding models. As the heat measured were quite small, we performed at least three experiments for each conditions (Figure S8a-b in the SI) and control experiments. Two different behaviors were observed depending on the used buffer. In the case of acetate buffer, TA/COL complexation exhibits an exothermic behavior (i.e. heat is released) all along the titration by TA up to 2 TA/COL molar ratio. This could be related to the formation of hydrogen bonds between amino groups and peptide bond $\mathrm{H}$-acceptor sites of COL and galloyl or hydroxyphenyl moieties of TA. In the case of citrate buffer, the change in enthalpy reaches zero at $0.28 \mathrm{TA} / \mathrm{COL}$ molar ratio, where saturation conditions seem to be reached. At this point, we observed COL aggregation in citrate but not in acetate buffer (Figure S8c-d in the SI). ITC results suggest that TA/COL binding is stronger in citrate buffer in comparison to acetate buffer.

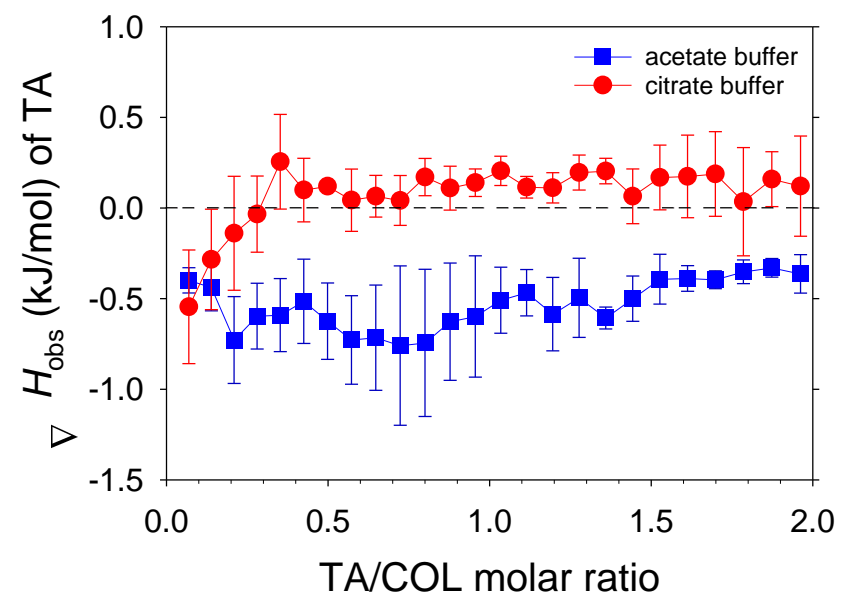

Figure 2: Molar enthalpy change $\left(\Delta H_{o b s}\right)$, measured by ITC, during the titration of COL by TA at $22^{\circ} \mathrm{C}$. The data represents the mean and standard deviation of at least three experiments. 
To determine the proportion of TA and COL in the films, XPS analyses were performed on $(\mathrm{COL} / \mathrm{TA})_{7}$ films in comparison to $\mathrm{COL}$ and TA monolayers obtained by dipping. XPS survey spectra revealed that carbon, oxygen, sodium and nitrogen are present in TA/COL films (Figure S9a-b in the SI). Figure 3 presents C1s high-resolution XPS spectra of the different samples. Detailed description of XPS spectra can be found in the SI.
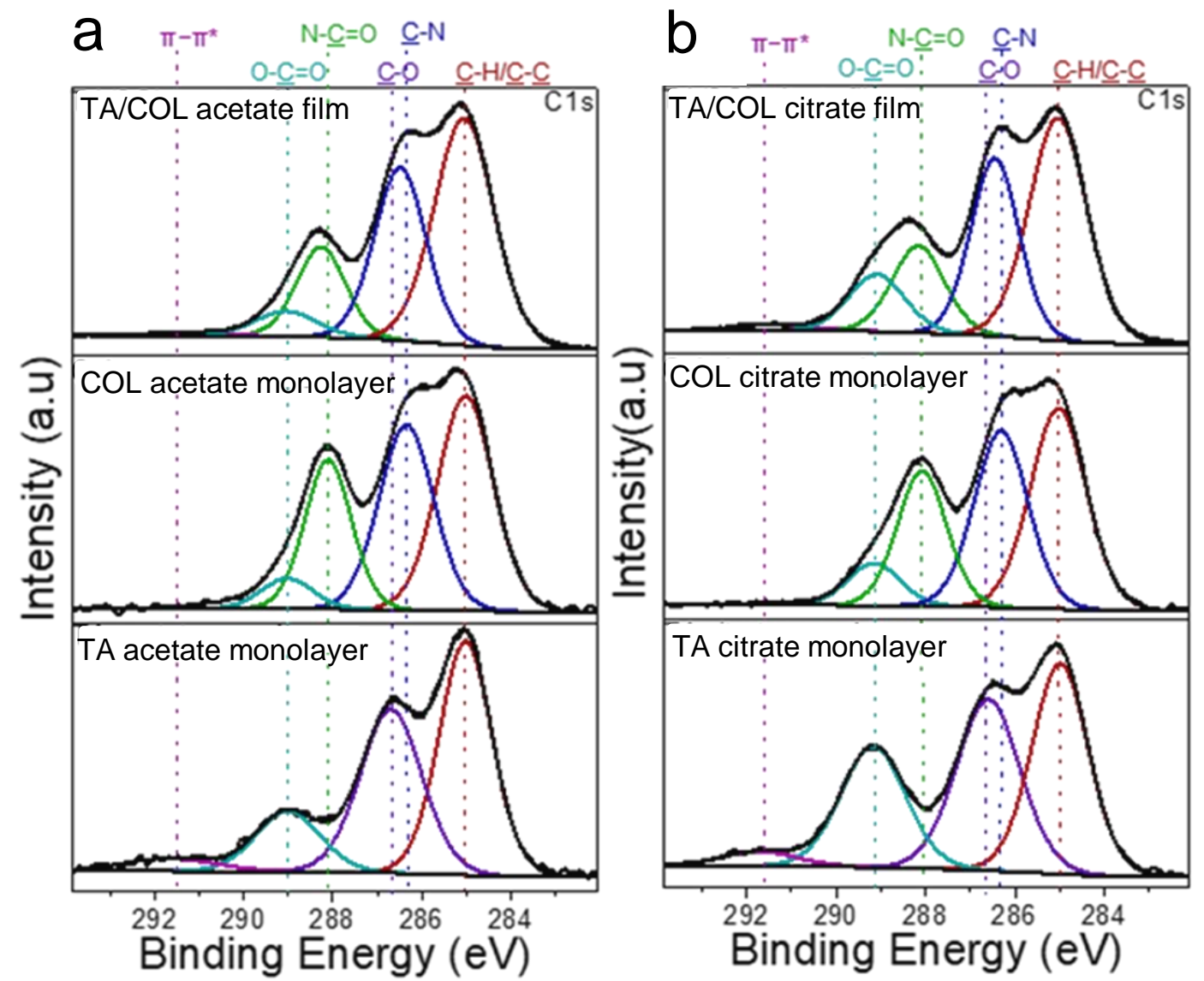

Figure 3: C1s XPS spectra of (COL/TA $)_{7}$ films, TA and COL monolayers obtained by using TA and COL solutions prepared in (a) acetate and (b) citrate buffers at $\mathrm{pH} 4$.

The COL/TA molar ratio of the films was calculated using the amount of oxidized carbon, corresponding to the 286,288 and $289 \mathrm{eV}$ peaks, present on all compounds and the total amount of nitrogen, present only for COL. The details on the calculations can be found in the SI. The COL/TA molar ratio was found at 1.4 for citrate films and 4.4 for acetate ones. A higher quantity 
of TA is incorporated for each adsorbed COL when citrate is used as buffer, which is probably related to the strong affinity between both compounds. Besides the presence of the Na1s peak, a higher contribution of the $\mathrm{O}-\mathrm{C}=\mathrm{O}$ peak $(289.1 \mathrm{eV})$ is observed for $\mathrm{TA}$ and $\mathrm{COL}$ citrate monolayers in comparison to TA and COL powders or acetate monolayers. Citrate molecules can interact through hydrogen bonds with TA molecules ${ }^{49}$ and through both hydrogen bonds ${ }^{50}$ and electrostatic interactions ${ }^{51}$ with $\mathrm{COL}$. When $\mathrm{TA} / \mathrm{COL} \mathrm{LbL}$ are built in citrate buffer, the incorporated citrate molecules interacting with $\mathrm{COL}$ through electrostatic interactions lead probably to supplementary H-bond sites for TA immobilization (Scheme 2).

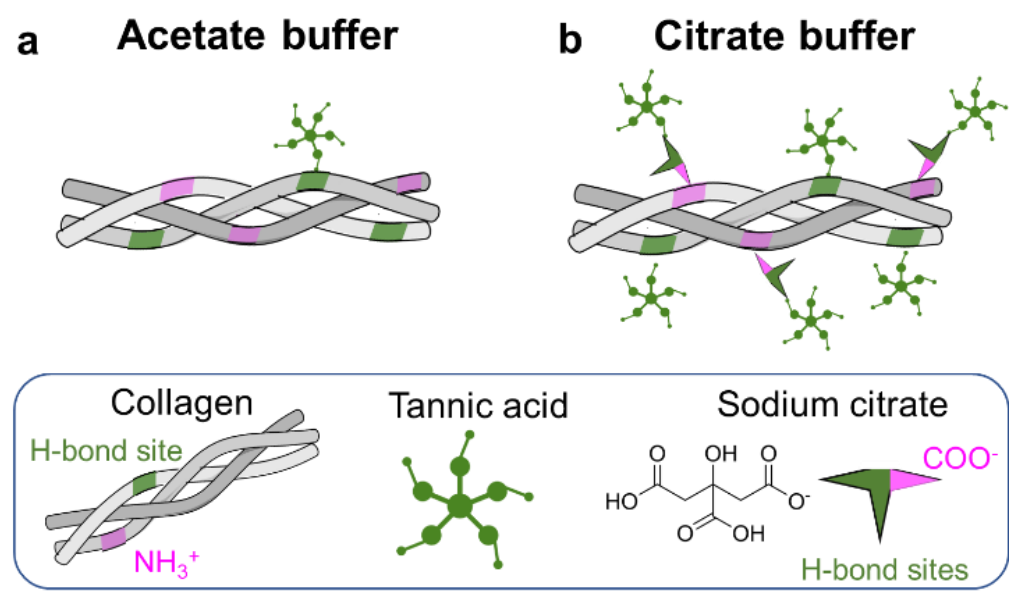

Scheme 2: Schematic illustration of TA/COL interactions in (a) acetate and (b) citrate buffers. At $\mathrm{pH} 4$, citric acid has one deprotonated carboxylic acid. Some elements were produced using Servier Medical Art image bank (https://smart.servier.com).

During the LbL buildup in acetate buffer followed by QCM-D, each deposition of TA and COL induced an increment in the frequency shift (Figure S1a in the SI) but the rinsing steps removed a non-negligible amount of the previous deposited layer suggesting a low binding between TA and COL (Scheme 3). The fibrillary structure of COL is maintained all over the buildup. 


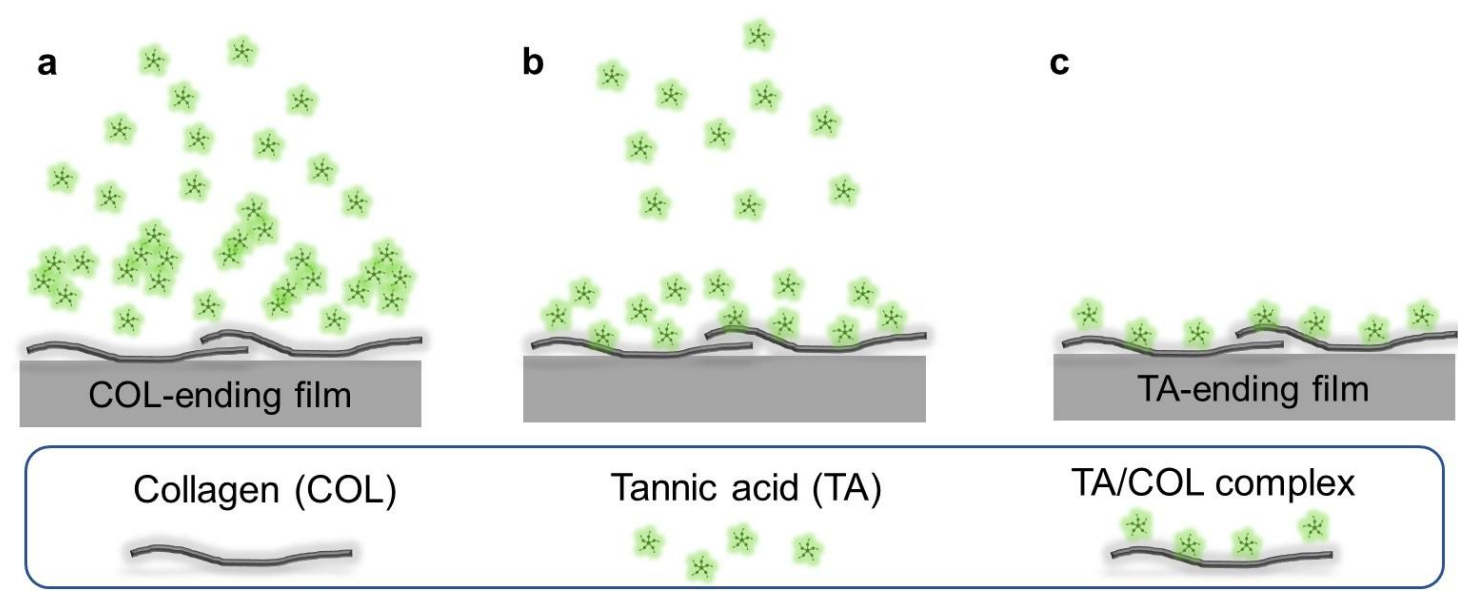

Scheme 3: Schematic illustration of TA/COL LbL buildup in acetate buffer. (a) When TA is put in contact with a COL-ending film, (b) TA molecules adsorbed on COL leading to TA/COL complexes. (c) The rinsing step removes the loosely bound TA molecules leading to TA-ending film. The fibrillary structure of COL is maintained during the buildup.

In the case of citrate buffer, the buildup is irregular with an increase in the frequency shift for COL and a decrease for TA (Figure S1b in the SI). An increase in thickness was observed for each TA/COL bilayer suggesting the adsorption of TA/COL complexes on the surface. The rinsing steps does not induce a supplementary loss of material, confirming the strong binding of TA/COL on the surface. A molecular model describing the formation of polyphenol/protein complexes, proposed by Williamson and co-workers, ${ }^{52}$ could explain this behavior and the granular topography of TA/COL citrate films. Upon addition of TA solution on COL-ending film, TA binds strongly to several sites of the adsorbed COL forming TA/COL compact complex inducing COL desorption and decrease in frequency shift (Scheme 4a). The presence of high concentration of TA in the supernatant leads to the dimerization (Scheme $4 \mathrm{~b}$ ) and then aggregation of TA/COL complexes (Scheme 4c) into larger particles that precipitate (Scheme 4d) on the surface of the LbL film. The TA/COL complex precipitation step thus allows the deposition of the next layer of COL. The deposition of TA/COL precipitates on the surface was 
obtained because the film buildup was done by pipetting the solutions on and from the QCM cell as performed in 24-well plates used for microbiology tests.

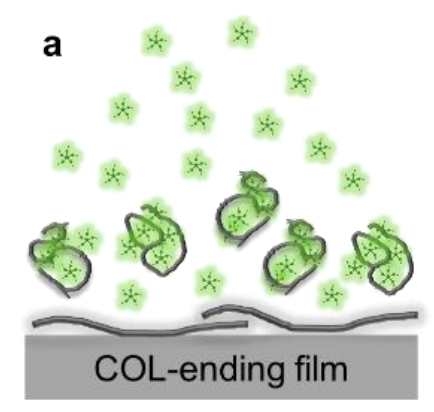

c
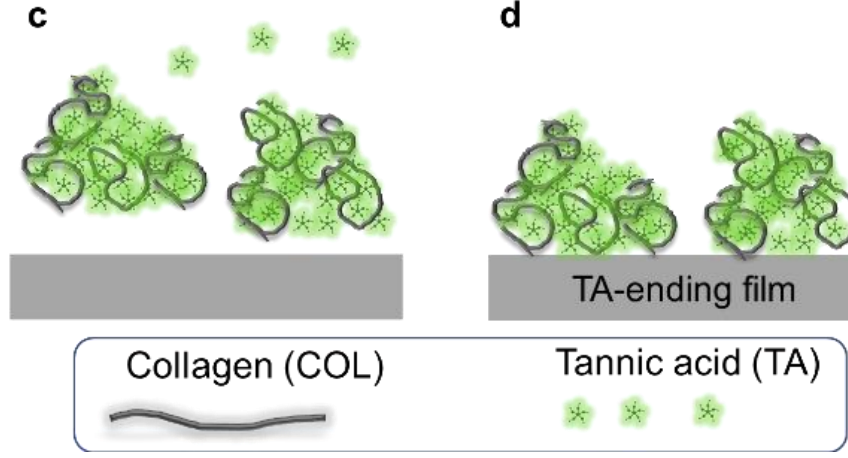

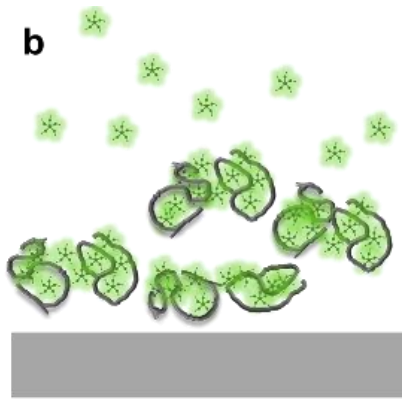

d

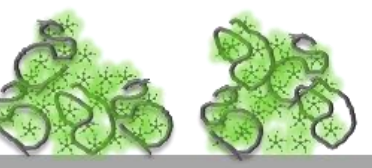

TA-ending film

Tannic acid (TA)

Scheme 4: Schematic illustration of TA/COL LbL buildup in citrate buffer. When TA is put in contact with a COL-ending film, there are (a) desorption of COL by TA leading to TA/COL complexes, (b) dimerization and (c) aggregation of TA/COL complexes followed by (d) their precipitation on the surface leading to the granular topography of TA/COL citrate films.

Film stability and TA release in physiological conditions. To evaluate the stability of the films in physiological conditions, TA/COL acetate and citrate films were incubated in PBS at pH 7.4 at room temperature overnight. A decrease in intensity of the $\mathrm{C}=\mathrm{O}$ stretching band of $\mathrm{TA}$ was observed while the amide I band of COL was unaffected (Figure 4a-b). The same experiment was performed by QCM-D. An immediate and small decrease in frequency shifts, for both film, was observed which stabilized within the first $30 \mathrm{~min}$ (figure S1 in the SI). The majority of the TA/COL films was stable with a loss in the total frequency shift of about $13 \%$ for both films. It 
should be emphasized that most of the COL-based LbL films reported in the literature required an additional crosslinking step to maintain their stability under physiological conditions. ${ }^{37,40,53-55}$
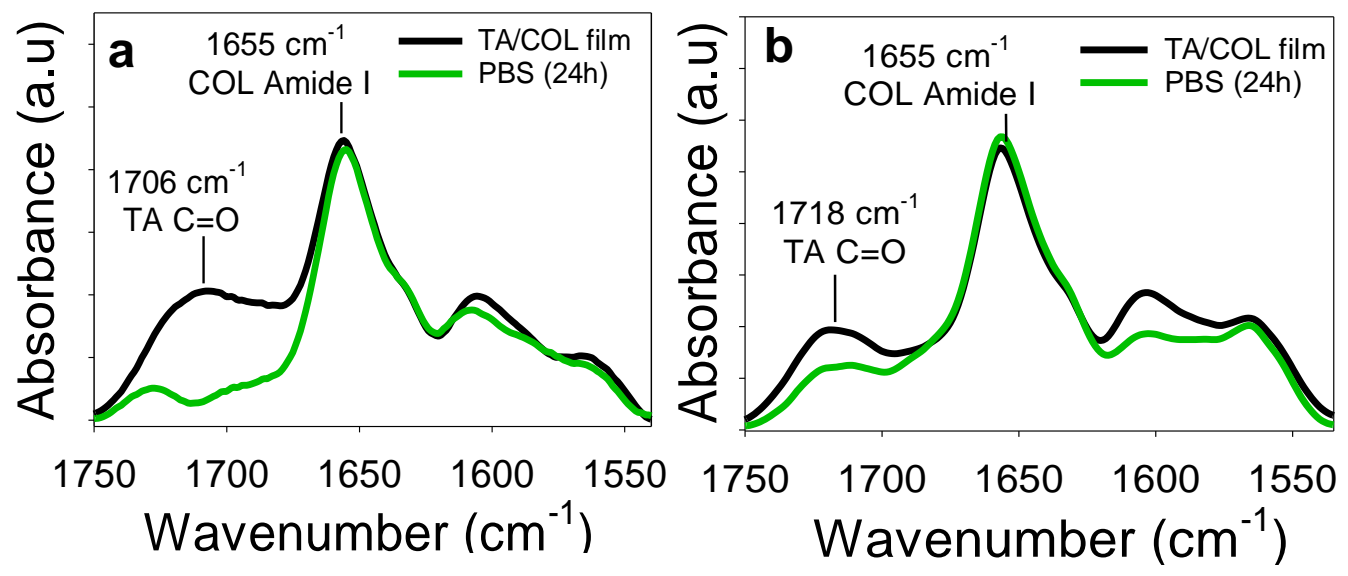

C

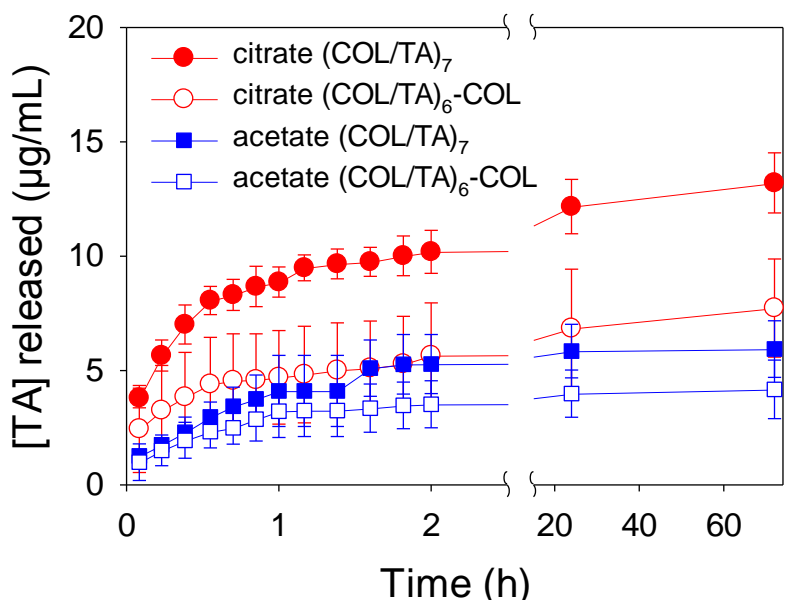

Figure 4: ATR-FTIR spectra of $(\mathrm{COL} / \mathrm{TA})_{6}-\mathrm{COL}$ films built at $\mathrm{pH} 4$ in deuterated acetate (a) and citrate (b) buffers before and after the contact with deuterated PBS pH 7.4. (c) Cumulative release profile of TA, from TA/COL films in contact with PBS pH 7.4 at room temperature.

The stability of the films towards $\mathrm{pH}$ and salt changes can be explained by the fact that (i) TA/COL LbL films are mainly based on hydrogen bonds and (ii) a sufficient amount of TA remains in the films to interact with COL after contact with PBS (Figure 4a-b). High stability of hydrogen-bonded neutral polymer/polyphenol LbL films towards $\mathrm{pH}$ and salt changes is explained by the pKa value of TA, reported at $8.5 .^{56}$ Recently, gelatin (denatured COL)/TA 
complexes were reported to possess two kinds of TA species: one strongly bound to the protein matrix (responsible for its stability in physiological conditions) and other loosely bound TA molecules. ${ }^{57}$ Weakly bound TA molecules can dissolve from the film's surface into physiological media and strongly bound TA can prevent COL to remove. The amount of TA released was determined by following the intensity of the absorbance measured at $277 \mathrm{~nm}$ (Figure 4c). TA/COL films were put in contact with PBS at room temperature similarly as in the FTIR and QCM-D experiments. The rate of release is highest in the first hour and stabilizes afterwards. TA ending films induced more TA release. After $72 \mathrm{~h}$ of contact, TA ended citrate films released twice as much TA than acetate films, $(13.2 \pm 1.3)$ and $(5.9 \pm 1.2) \mu \mathrm{g} / \mathrm{mL}$, respectively (Figure 4c). Granular citrate films release a higher amount of TA than acetate films, because of supplementary TA molecules immobilized by electrostatic interactions thanks to citrate (Scheme 5).

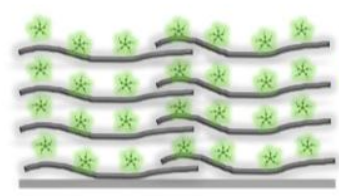

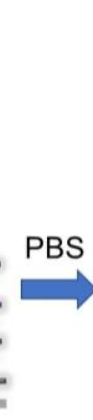

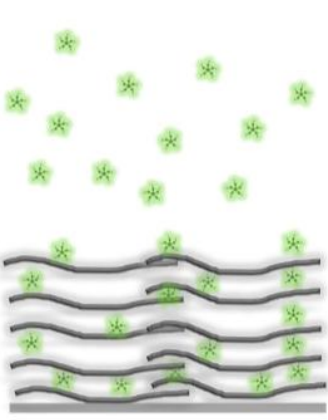

b

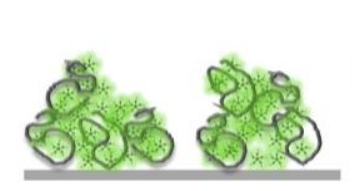

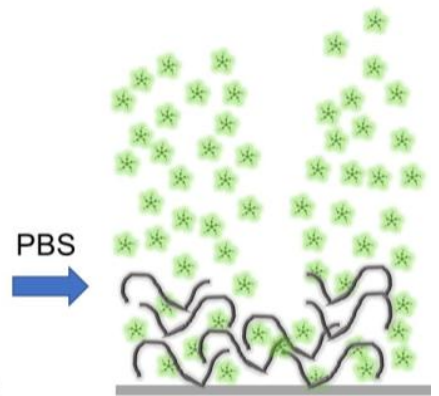

Scheme 5: Schematic representation of TA release obtained from TA/COL (a) acetate and (b) citrate films when put in contact with PBS. Citrate films release a higher amount of TA than acetate films because of supplementary TA molecules immobilized by electrostatic interactions thanks to citrate.

To mimic biological conditions of bacteria and cell culture, the release kinetics of TA was also followed at $37^{\circ} \mathrm{C}$ in HEPES and HEPES/ $\mathrm{NaCl}$ buffers $\mathrm{pH} 7.4$, respectively (Figure $\mathrm{S} 10$ in the SI). Similar results were obtained with a higher release in the presence of $150 \mathrm{mM} \mathrm{NaCl}$ in the 
case of citrate films, which confirms the contribution of ionic interactions in these films. ${ }^{46}$ No compensation of charges are necessary in the case of acetate films. But in the case of citrate films, citrate molecules, interacting through electrostatic interactions with COL, are also released and the charge compensation is obtained thanks to counter ions present in PBS or the culture medium.

Antibacterial assays and human cell viability. TA being well known to kill planktonic bacteria, $^{58}$ the antibacterial activity of $\mathrm{TA} / \mathrm{COL}$ multilayer films was assessed against Staphylococcus aureus (S. aureus), a gram-positive strain which is one of the most virulent bacteria leading to high rates of device-related systemic infections and mortality ${ }^{59}$ and Escherichia Coli (E. Coli), a gram-negative strain mainly found on the surface of catheters. The viability of bacteria was determined in $\mathrm{MH}$ broth after 24 and $48 \mathrm{~h}$ of contact with TA/COL acetate and citrate films. To this purpose, the supernatant was plated on agar petri dishes to enumerate the colony forming units (CFU) present in their planktonic state. A high antibacterial effect against $S$. aureus is observed for TA/COL citrate films and not for TA/COL acetate ones (Figure 5a). In HEPES buffer at $37^{\circ} \mathrm{C}$, medium mimicking $\mathrm{MH}$ broth, no significant difference in TA release were observed between $(\mathrm{COL} / \mathrm{TA})_{6}-\mathrm{COL}$ citrate and $(\mathrm{COL} / \mathrm{TA})_{7}$ acetate films, with $(6.0 \pm 0.7)$ and $(5.9 \pm 2.2) \mu \mathrm{g} / \mathrm{mL}$ after $24 \mathrm{~h}$, respectively (Figure S10a in the SI). However, a dramatic difference in bacterial viability after $24 \mathrm{~h}$ of contact is observed with only $(4 \pm 4) \mathrm{CFU}$ counted on the citrate films against $(2.8 \pm 0.7) \times 10^{8} \mathrm{CFU}$ on the acetate ones. Thus, the antibacterial property of TA/COL citrate films is not linked to the total amount of TA released, which is by far lower than the minimal inhibitory concentration of TA against $S$. aureus (around $100 \mu \mathrm{g} / \mathrm{mL})^{28,57}$ 

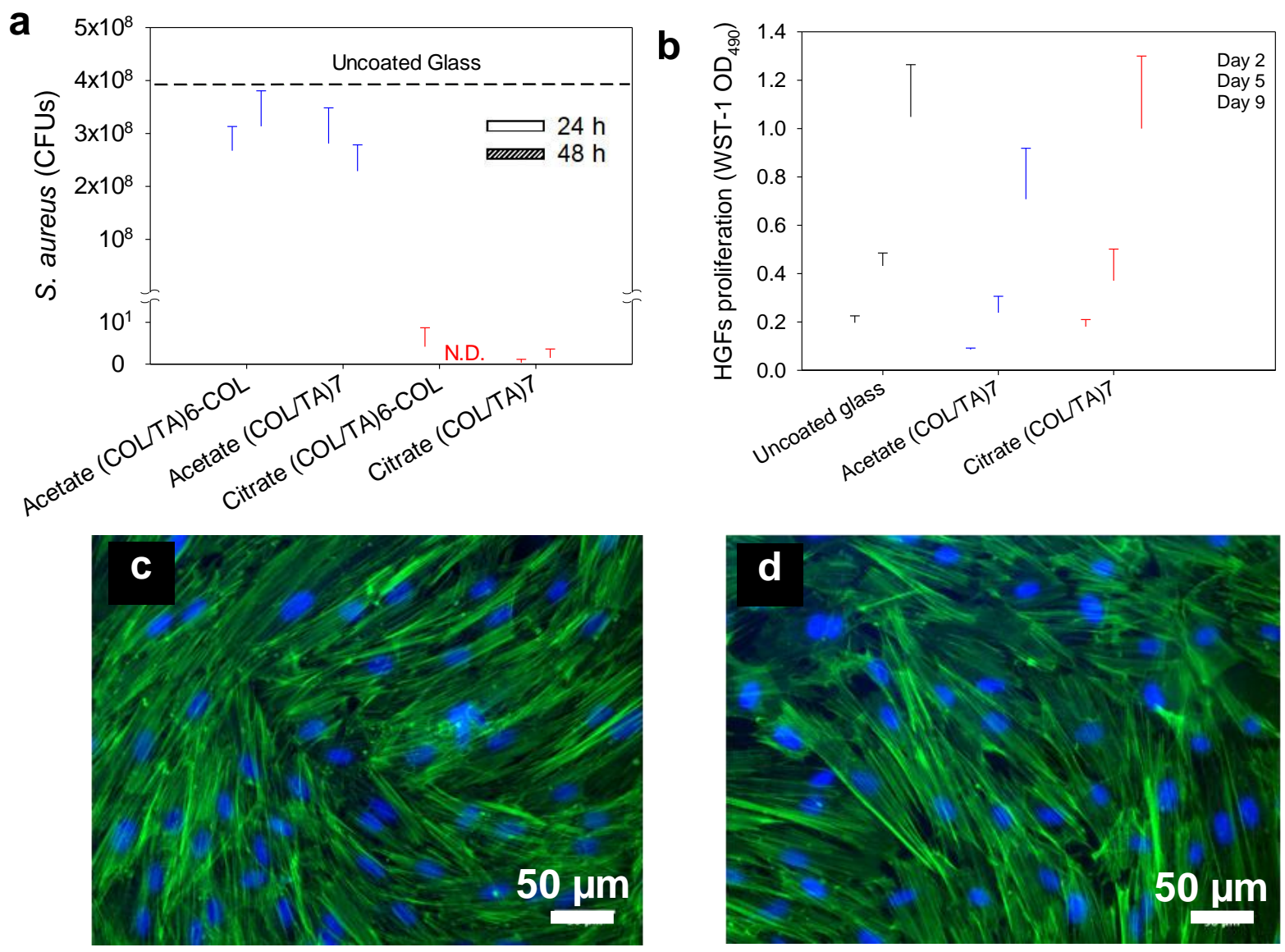

Figure 5: (a) CFU of S. aureus from the supernatant of TA/COL films after $24 \mathrm{~h}$ and $48 \mathrm{~h}$ of contact. N.D. means not detected: no CFU were observed. The dashed line represents the CFU obtained from the bacterial supernatant in contact with an uncoated glass. (b) HGFs viability on $(\mathrm{COL} / \mathrm{TA})_{7}$ films, determined by WST-1 mitochondrial assay. Cytoskeleton labelling (green = Factin, blue $=$ nuclei $)$ after 15 days of culture on $(\mathrm{COL} / \mathrm{TA})_{7}$ acetate $(\mathrm{c})$ and citrate $(\mathrm{d})$ films .

TA/COL acetate films present several colonies after $24 \mathrm{~h}$ of contact. In contrast, no bacteria were observed on the surface of TA/COL citrate films after $24 \mathrm{~h}$ of contact (Figure S11 in the SI). After $4 \mathrm{~h}$ of contact with TA/COL citrate films, bacteria with cell membrane disruption are observed (Figure S12a in the SI). TA molecules were reported to destroy the integrity of the $S$. aureus cell wall, by interacting with the peptidoglycans of the bacterial membrane. ${ }^{28}$ The 
absence of bacteria after $24 \mathrm{~h}$ of contact is probably due to the severe damage of cell membrane leading to cell death and detachment from TA/COL films. It could also be explained by the protocol applied on the samples which includes a smooth PBS rinsing before fixation. However, some bacterial debris are visible at low magnification image (Figure S11c in the SI). TA/COL citrate films exhibit a granular topography rich in TA in contrast to acetate ones. After $24 \mathrm{~h}$ of contact with PBS, this granular topography disappeared because of TA release, showing fibrillary structure of COL (Figure S12b-c in the SI). The dissolution of TA/COL granular aggregates leads probably to a concentration of TA released near the surface of the films higher than the MIC (Scheme 6). Incubated without agitation during the assay, bacteria were deposited on the surface of the films by sedimentation. A local release-killing effect is thus observed for TA/COL citrate films in contrast to acetate ones.

a

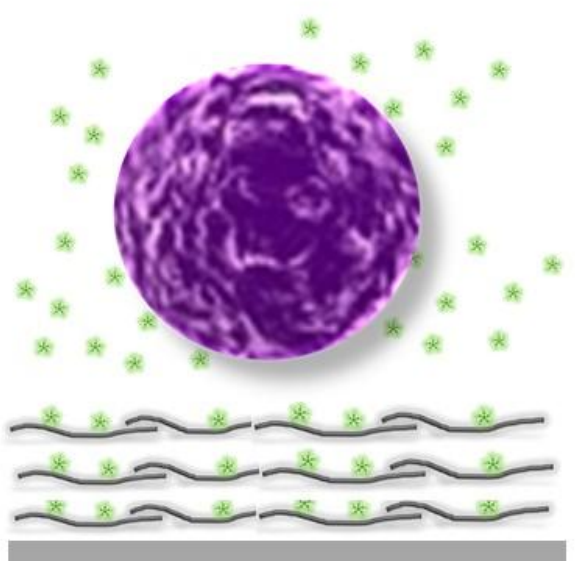

b

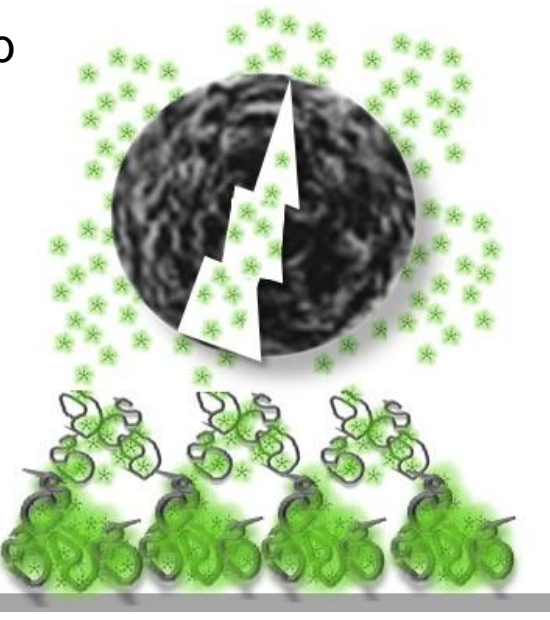

Scheme 6: Schematic representation of TA release from TA/COL films in contact S. aureus for acetate films (a) and citrate films (b). A local release-killing effect toward bacteria is observed only for citrate films. Granular aggregates of TA/COL dissolution induce the local release of TA in a concentration above its MIC. 
Concerning E. Coli, a decrease in the normalized growth of $45 \%$ was observed after $24 \mathrm{~h}$ of contact with $(\mathrm{COL} / \mathrm{TA})_{7}$ citrate films (Figure S13 in the SI). It is known that the bactericidal activity of tannins is lower against gram-negative bacteria than against gram-positive bacteria. This is due to the presence of the lipopolysaccharide on the outer membrane of gram-negative bacteria. ${ }^{28}$ Finally, it is important to ensure that the films are not cytotoxic towards mammalian cells. The behavior of human gingival fibroblasts (HGFs) cultivated on TA/COL acetate and citrate films were compared to an uncoated glass substrate. Proliferation assay and DNA quantification show no significant differences in HGFs proliferation for 9 days whatever the studied conditions, i.e. TA or COL ended-films (Figure 5b and Figure S14 in the SI). Cell integrity of HGFs was evaluated by cytoskeleton labelling. After 15 days of culture, a confluent layer was obtained on all the tested TA/COL films (Figure 5c-d and Figure S15 in the SI). A typical fibroblastic cell shape is observed with polymerized F-actin fibres lying parallel to each other. These results demonstrate the absence of TA/COL cytotoxic effect in both buffers.

Conclusion. In this study, we reported buffer dependent antibacterial property of TA/COL films. Because of the solubility issue of $\mathrm{COL}$, acetate and citrate buffers at $\mathrm{pH} 4$ were used to build the LbL films, affecting their physico-chemical as well as the antibacterial properties. Specifically, complexation strengths between TA and COL are different in the presence of acetate or citrate affecting the LbL deposition. In comparison to acetate buffer TA/COL binding is stronger in citrate buffer leading to a higher immobilization of TA and to the granular topography of TA/COL citrate films, providing higher specific surface. A local release-killing effect towards $S$. aureus was obtained for TA/COL citrate films thanks to their granular topography. The developed LbL films revealed no cytotoxic effect towards human gingival derived fibroblasts. 
This work constitutes an important step toward the use of polyphenols as antimicrobial agent when incorporated in LbL films.

\section{ASSOCIATED CONTENT}

Supporting Information. QCM-D data of TA/COL buildup, Dissipation vs frequency shift obtained by QCM of TA/COL films, 2D and 3D AFM images of unscratched and scratched TA/COL films at different numbers of deposited layers, Thickness and roughness of TA/COL films determined by AFM, CD and FTIR spectra of TA/COL films at different number of deposited layer with detailed description, ITC data for three experiments of COL titration by TA, XPS survey spectra, detailed description of Figure 3 and calculation method to evaluate COL/TA molar ratio, TA release from TA/COL films in HEPES and HEPES-NaCl buffers at $\mathrm{pH} 7.4$ and $37^{\circ} \mathrm{C}$, SEM images of TA/COL films after $24 \mathrm{~h}$ and $4 \mathrm{~h}$ of contact with $S$. aureus, HGFs viability and cytoskeleton labeling on TA/COL films. The following file (pdf) is free of charge via the Internet at http://pubs.acs.org.

\section{AUTHOR INFORMATION}

\section{Corresponding Author}

* Fouzia Boulmedais, fouzia.boulmedais@ics-cnrs.unistra.fr

\section{Author Contributions}

The manuscript was written through contributions of all authors. All authors have given approval to the final version of the manuscript.

\section{Funding Sources}


Institut Carnot MICA DIAART project and Higher Education Commission's Pakistan is acknowledge for financial support.

\section{ACKNOWLEDGMENT}

C. Mauprivez is acknowledged for providing gingival tissues. MHI thanks the Higher Education Commission's (HEC) Pakistan for his Ph.D. scholarship. Institut Carnot MICA (DIAART project) is acknowledged for financial support.

\section{REFERENCES}

(1) Zhao, L.; Chu, P. K.; Zhang, Y.; Wu, Z. Antibacterial Coatings on Titanium Implants. J. Biomed. Mater. Res., Part B 2009, 91B, 470-480.

(2) Carmona-Ribeiro, A. M. Self-Assembled Antimicrobial Nanomaterials. Int. J. Environ. Res. Public Health 2018, 15, 1408.

(3) Wang, M. Q.; Tang, T. T. Surface Treatment Strategies to Combat Implant-Related Infection from the Beginning. J. Orthop. Transl. 2019, 17, 42-54.

(4) Decher, G. Fuzzy Nanoassemblies: Toward Layered Polymeric Multicomposites. Science 1997, 277, 1232-1237.

(5) Bertrand, P.; Jonas, A.; Laschewsky, A.; Legras, R. Ultrathin Polymer Coatings by Complexation of Polyelectrolytes at Interfaces : Suitable Materials, Structure and Properties. Macromol. Rapid Commun. 2000, 21, 319-348.

(6) Kharlampieva, E.; Kozlovskaya, V.; Sukhishvili, S. A. Layer-by-Layer Hydrogen-Bonded Polymer Films: From Fundamentals to Applications. Adv. Mater. 2009, 21, 3053-3065.

(7) Kharlampieva, E.; Sukhishvili, S. A. Hydrogen-Bonded Layer-by-Layer Polymer Films. Polym. Rev. 2006, 46, 377-395.

(8) Séon, L.; Lavalle, P.; Schaaf, P.; Boulmedais, F. Polyelectrolyte Multilayers: A Versatile Tool for Preparing Antimicrobial Coatings. Langmuir 2015, 31, 12856-12872.

(9) Pahal, S.; Gakhar, R.; Raichur, A. M.; Varma, M. M. Polyelectrolyte Multilayers for BioApplications: Recent Advancements. IET Nanobiotechnol. 2017, 11, 903-908.

(10) Schmolke, H.; Demming, S.; Edlich, A.; Magdanz, V.; Buttgenbach, S.; Franco-Lara, E.; Krull, R.; Klages, C. P. Polyelectrolyte Multilayer Surface Functionalization of Poly(Dimethylsiloxane) (Pdms) for Reduction of Yeast Cell Adhesion in Microfluidic Devices. Biomicrofluidics 2010, 4, 12.

(11) Lichter, J. A.; Thompson, M. T.; Delgadillo, M.; Nishikawa, T.; Rubner, M. F.; Van Vliet, K. J. Substrata Mechanical Stiffness Can Regulate Adhesion of Viable Bacteria.

Biomacromolecules 2008, 9, 1571-1578.

(12) Saha, N.; Monge, C.; Dulong, V.; Picart, C.; Glinel, K. Influence of Polyelectrolyte Film Stiffness on Bacterial Growth. Biomacromolecules 2013, 14, 520-528.

(13) Fu, J.; Ji, J.; Yuan, W.; Shen, J. Construction of Anti-Adhesive and Antibacterial Multilayer Films Via Layer-by-Layer Assembly of Heparin and Chitosan. Biomaterials 2005, 26, 66846692. 
(14) Richert, L.; Lavalle, P.; Payan, E.; Shu, X. Z.; Prestwich, G. D.; Stoltz, J. F.; Schaaf, P.; Voegel, J. C.; Picart, C. Layer by Layer Buildup of Polysaccharide Films: Physical Chemistry and Cellular Adhesion Aspects. Langmuir 2004, 20, 448-458.

(15) Bratskaya, S.; Marinin, D.; Simon, F.; Synytska, A.; Zschoche, S.; Busscher, H. J.; Jager, D.; van der Mei, H. C. Adhesion and Viability of Two Enterococcal Strains on Covalently Grafted Chitosan and Chitosan/Kappa-Carrageenan Multilayers. Biomacromolecules 2007, 8, 2960-2968.

(16) Lichter, J. A.; Rubner, M. F. Polyelectrolyte Multilayers with Intrinsic Antimicrobial Functionality: The Importance of Mobile Polycations. Langmuir 2009, 25, 7686-7694.

(17) Mutschler, A.; Tallet, L.; Rabineau, M.; Dollinger, C.; Metz-Boutigue, M.-H.; Schneider, F.; Senger, B.; Vrana, N. E.; Schaaf, P.; Lavalle, P. Unexpected Bactericidal Activity of Poly(Arginine)/Hyaluronan Nanolayered Coatings. Chem. Mat. 2016, 28, 8700-8709.

(18) Alkekhia, D.; Shukla, A. Influence of Poly-L-Lysine Molecular Weight on Antibacterial Efficacy in Polymer Multilayer Films. J. Biomed. Mater. Res., Part A 2019, 107, 1324-1339.

(19) Cui, D.; Szarpak, A.; Pignot-Paintrand, I.; Varrot, A.; Boudou, T.; Detrembleur, C.; Jerome, C.; Picart, C.; Auzely-Velty, R. Contact-Killing Polyelectrolyte Microcapsules Based on Chitosan Derivatives. Adv. Funct. Mater. 2010, 20, 3303-3312.

(20) Yang, W. J.; Pranantyo, D.; Neoh, K. G.; Kang, E. T.; Teo, S. L. M.; Rittschof, D. Layerby-Layer Click Deposition of Functional Polymer Coatings for Combating Marine Biofouling. Biomacromolecules 2012, 13, 2769-2780.

(21) Mutschler, A.; Betscha, C.; Ball, V.; Senger, B.; Vrana, N. E.; Boulmedais, F.; Schroder, A.; Schaaf, P.; Lavalle, P. Nature of the Polyanion Governs the Antimicrobial Properties of Poly(Arginine)/Polyanion Multilayer Films. Chem Mater. 2017, 29, 3195-3201.

(22) Malcher, M.; Volodkin, D.; Heurtault, B.; Andre, P.; Schaaf, P.; Möhwald, H.; Voegel, J.C.; Sokolowski, A.; Ball, V.; Boulmedais, F.; Frisch, B. Embedded Silver Ions-Containing Liposomes in Polyelectrolyte Multilayers: Cargos Films for Antibacterial Agents. Langmuir 2008, 24, 10209-10215.

(23) Shi, Z.; Neoh, K. G.; Zhong, S. P.; Yung, L. Y. L.; Kang, E. T.; Wang, W. In Vitro Antibacterial and Cytotoxicity Assay of Multilayered Polyelectrolyte-Functionalized Stainless Steel. J. Biomed. Mater. Res. Part A 2006, 76A, 826-834.

(24) Moskowitz, J. S.; Blaisse, M. R.; Samuel, R. E.; Hsu, H. P.; Harris, M. B.; Martin, S. D.; Lee, J. C.; Spector, M.; Hammond, P. T. The Effectiveness of the Controlled Release of Gentamicin from Polyelectrolyte Multilayers in the Treatment of Staphylococcus Aureus Infection in a Rabbit Bone Model. Biomaterials 2010, 31, 6019-6030.

(25) Shukla, A.; Avadhany, S. N.; Fang, J. C.; Hammond, P. T. Tunable Vancomycin Releasing Surfaces for Biomedical Applications. Small 2010, 6, 2392-2404.

(26) Pavlukhina, S.; Lu, Y. M.; Patimetha, A.; Libera, M.; Sukhishvili, S. Polymer Multilayers with Ph-Triggered Release of Antibacterial Agents. Biomacromolecules 2010, 11, 3448-3456.

(27) Cado, G.; Aslam, R.; Séon, L.; Garnier, T.; Fabre, R.; Parat, A.; Chassepot, A.; Voegel, J.C.; Senger, B.; Schneider, F.; Frère, Y.; Jierry, L.; Schaaf, P.; Kerdjoudj, H.; Metz-Boutigue, M.H.; Boulmedais, F. Self-Defensive Biomaterial Coating against Bacteria and Yeasts:

Polysaccharide Multilayer Film with Embedded Antimicrobial Peptide. Adv. Funct. Mater 2013, 23, 4801-4809.

(28) Dong, G.; Liu, H.; Yu, X.; Zhang, X.; Lu, H.; Zhou, T.; Cao, J. Antimicrobial and AntiBiofilm Activity of Tannic Acid against Staphylococcus Aureus. Nat. Prod. Res. 2018, 32, 22252228. 
(29) Ren, P.-F.; Yang, H.-C.; Liang, H.-Q.; Xu, X.-L.; Wan, L.-S.; Xu, Z.-K. Highly Stable, Protein-Resistant Surfaces Via the Layer-by-Layer Assembly of Poly(Sulfobetaine Methacrylate) and Tannic Acid. Langmuir 2015, 31, 5851-5858.

(30) Qi, X.; Zhang, D.; Ma, Z.; Cao, W.; Hou, Y.; Zhu, J.; Gan, Y.; Yang, M. An Epidermis-Like Hierarchical Smart Coating with a Hardness of Tooth Enamel. Acs Nano 2018, 12, 1062-1073. (31) Shukla, A.; Fang, J. C.; Puranam, S.; Jensen, F. R.; Hammond, P. T. Hemostatic Multilayer Coatings. Adv. Mater. 2012, 24, 492-496.

(32) Park, J. H.; Choi, S.; Moon, H. C.; Seo, H.; Kim, J. Y.; Hong, S. P.; Lee, B. S.; Kang, E.; Lee, J.; Ryu, D. H.; Choi, I. S. Antimicrobial Spray Nanocoating of Supramolecular Fe(Iii)Tannic Acid Metal-Organic Coordination Complex: Applications to Shoe Insoles and Fruits. Sci Rep. 2017, 7.

(33) Zhuk, I.; Jariwala, F.; Attygalle, A. B.; Wu, Y.; Libera, M. R.; Sukhishvili, S. A. SelfDefensive Layer-by-Layer Films with Bacteria-Triggered Antibiotic Release. ACS Nano 2014, 8, 7733-7745.

(34) Xu, G.; Pranantyo, D.; Zhang, B.; Xu, L.; Neoh, K.-G.; Kang, E.-T. Tannic Acid Anchored Layer-by-Layer Covalent Deposition of Parasin I Peptide for Antifouling and Antimicrobial Coatings. RSC Adv. 2016, 6, 14809-14818.

(35) Kumorek, M.; Minisy, I. M.; Krunclová, T.; Voršiláková, M.; Venclíková, K.; Mázl Chánová, E.; Janoušková, O.; Kubies, D. Ph-Responsive and Antibacterial Properties of SelfAssembled Multilayer Films Based on Chitosan and Tannic Acid. Mater. Sci. Eng., C 2020, 109, 110493.

(36) Grant, G. G. S.; Koktysh, D. S.; Yun, B.; Matts, R. L.; Kotov, N. A. Layer-by-Layer Assembly of Collagen Thin Films: Controlled Thickness and Biocompatibility. Biomed. Microdevices 2001, 3, 301-306.

(37) Chaubaroux, C.; Vrana, E.; Debry, C.; Schaaf, P.; Senger, B.; Voegel, J. C.; Haikel, Y.; Ringwald, C.; Hemmerle, J.; Lavalle, P.; Boulmedais, F. Collagen-Based Fibrillar Multilayer Films Cross-Linked by a Natural Agent. Biomacromolecules 2012, 13, 2128-2135.

(38) Chen, J. L.; Li, Q. L.; Chen, J. Y.; Chen, C.; Huang, N. Improving Blood-Compatibility of Titanium by Coating Collagen-Heparin Multilayers. Appl. Surf. Sci. 2009, 255, 6894-6900. (39) Gong, Y.; Zhu, Y.; Liu, Y.; Ma, Z.; Gao, C.; Shen, J. Layer-by-Layer Assembly of Chondroitin Sulfate and Collagen on Aminolyzed Poly(L-Lactic Acid) Porous Scaffolds to Enhance Their Chondrogenesis. Acta Biomater 2007, 3, 677-685.

(40) Johansson, J. Å.; Halthur, T.; Herranen, M.; Söderberg, L.; Elofsson, U.; Hilborn, J. Buildup of Collagen and Hyaluronic Acid Polyelectrolyte Multilayers. Biomacromolecules 2005, 6, 1353-1359.

(41) Voinova, M. V.; Rodahl, M.; Jonson, M.; Kasemo, B. Viscoelastic Acoustic Response of Layered Polymer Films at Fluid-Solid Interfaces: Continuum Mechanics Approach. Phys. Scr. 1999, 59, 391-396.

(42) Scofield, J. H. Hartree-Slater Subshell Photoionization Cross-Sections at 1254 and 1487ev. J. Electron. Spectrosc. 1976, 8, 129-137.

(43) Hook, F.; Rodahl, M.; Kasemo, B.; Brzezinski, P. Structural Changes in Hemoglobin During Adsorption to Solid Surfaces: Effects of Ph, Ionic Strength, and Ligand Binding. Proc. Natl. Acad. Sci. U. S. A. 1998, 95, 12271-12276.

(44) Belegrinou, S.; Mannelli, I.; Lisboa, P.; Bretagnol, F.; Valsesia, A.; Ceccone, G.; Colpo, P.; Rauscher, H.; Rossi, F. Ph-Dependent Immobilization of Proteins on Surfaces Functionalized by 
Plasma-Enhanced Chemical Vapor Deposition of Poly(Acrylic Acid)- and Poly(Ethylene Oxide)-Like Films. Langmuir 2008, 24, 7251-7261.

(45) Velmurugan, P.; Singam, E. R.; Jonnalagadda, R. R.; Subramanian, V. Investigation on Interaction of Tannic Acid with Type I Collagen and Its Effect on Thermal, Enzymatic, and Conformational Stability for Tissue Engineering Applications. Biopolymers 2014, 101, 471-483.

(46) Han, Y.; Lin, Z.; Zhou, J.; Yun, G.; Guo, R.; Richardson, J. J.; Caruso, F. PolyphenolMediated Assembly of Proteins for Engineering Functional Materials. Angew. Chem., Int. Ed. 2020, DOI: 10.1002/anie.202002089.

(47) Heijmen, F. H.; du Pont, J. S.; Middelkoop, E.; Kreis, R. W.; Hoekstra, M. J. Cross-Linking of Dermal Sheep Collagen with Tannic Acid. Biomaterials 1997, 18, 749-754.

(48) Frazier, R. A.; Papadopoulou, A.; Mueller-Harvey, I.; Kissoon, D.; Green, R. J. Probing Protein-Tannin Interactions by Isothermal Titration Microcalorimetry. J. Agric. Food Chem. 2003, 51, 5189-5195.

(49) Ranoszek-Soliwoda, K.; Tomaszewska, E.; Socha, E.; Krzyczmonik, P.; Ignaczak, A.; Orlowski, P.; Krzyzowska, M.; Celichowski, G.; Grobelny, J. The Role of Tannic Acid and Sodium Citrate in the Synthesis of Silver Nanoparticles. J. Nanopart. Res. 2017, 19, 273. (50) Shao, C.; Zhao, R.; Jiang, S.; Yao, S.; Wu, Z.; Jin, B.; Yang, Y.; Pan, H.; Tang, R. Citrate Improves Collagen Mineralization Via Interface Wetting: A Physicochemical Understanding of Biomineralization Control. Adv. Mater. 2018, 30, 1704876.

(51) Delgado-Lopez, J. M.; Bertolotti, F.; Lyngso, J.; Pedersen, J. S.; Cervellino, A.; Masciocchi, N.; Guagliardi, A. The Synergic Role of Collagen and Citrate in Stabilizing Amorphous Calcium Phosphate Precursors with Platy Morphology. Acta Biomater 2017, 49, 555-562.

(52) Jobstl, E.; O'Connell, J.; Fairclough, J. P. A.; Williamson, M. P. Molecular Model for Astringency Produced by Polyphenol/Protein Interactions. Biomacromolecules 2004, 5, 942-949. (53) Chaubaroux, C.; Perrin-Schmitt, F.; Senger, B.; Vidal, L.; Voegel, J. C.; Schaaf, P.; Haikel, Y.; Boulmedais, F.; Lavalle, P.; Hemmerle, J. Cell Alignment Driven by Mechanically Induced Collagen Fiber Alignment in Collagen/Alginate Coatings. Tissue Eng., Part C 2015, 21, 881888.

(54) Ao, H.; Zong, J.; Nie, Y.; Wan, Y.; Zheng, X. An In vivo Study on the Effect of Coating Stability on Osteointegration Performance of Collagen/Hyaluronic Acid Multilayer Modified Titanium Implants. Bioact. Mater. 2018, 3, 97-101.

(55) Ao, H.; Xie, Y.; Tan, H.; Yang, S.; Li, K.; Wu, X.; Zheng, X.; Tang, T. Fabrication and in Vitro Evaluation of Stable Collagen/Hyaluronic Acid Biomimetic Multilayer on Titanium Coatings. J. R. Soc., Interface 2013, 10, 20130070.

(56) Erel-Unal, I.; Sukhishvili, S. A. Hydrogen-Bonded Multilayers of a Neutral Polymer and a Polyphenol. Macromolecules 2008, 41, 3962-3970.

(57) Reitzer, F.; Berber, E.; Halgand, J.; Ball, V.; Meyer, F. Use of Gelatin as Tannic Acid Carrier for Its Sustained Local Delivery. Pharm. Front. 2020, e200002.

(58) Payne, D. E.; Martin, N. R.; Parzych, K. R.; Rickard, A. H.; Underwood, A.; Boles, B. R. Tannic Acid Inhibits Staphylococcus Aureus Surface Colonization in an Isaa-Dependent Manner. Infect. Immun. 2013, 81, 496-504.

(59) Katneni, R.; Hedayati, S. S. Central Venous Catheter-Related Bacteremia in Chronic Hemodialysis Patients: Epidemiology and Evidence-Based Management. Nat. Clin. Pract. Nephrol. 2007, 3, 256-266. 
Table of Content

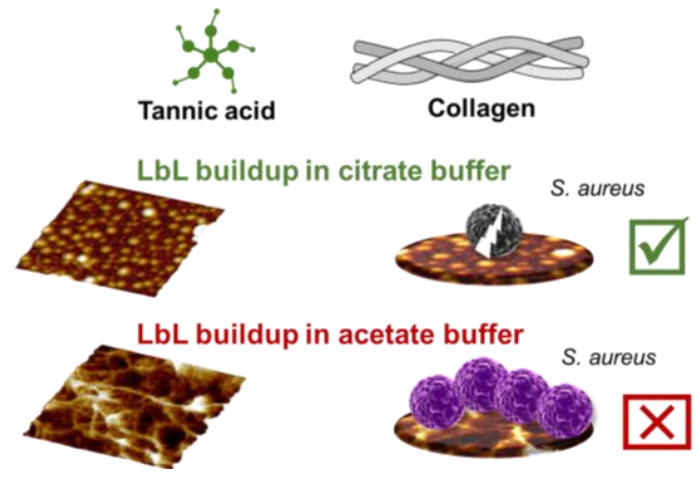

